\title{
Prophylaxis - A key component in malaria control
}

\author{
Van Zyl, RL \\ Pharmacology Division, Department of Pharmacy and Pharmacology, School of Therapeutic Sciences, WITS Research Institute of Malaria \\ (WRIM), MRC Collaborating Centre for Multidisciplinary Research on Malaria, Faculty of Health Sciences, University of Witwatersrand, \\ Johannesburg \\ *Corresponding author, email: Robyn.vanZyl@wits.ac.za
}

\begin{abstract}
With the summer holidays fast approaching, holidaymakers will be planning their trip across Africa and the globe. Patients need to be aware of the risks of mosquito bites and contracting malaria. Malaria is endemic in the Limpopo, Mpumalanga and Northern KwaZulu-Natal provinces, with several cases of travel or Odyssean malaria being reported around South Africa. Prophylaxis is key in reducing the risk of infection by malaria. The use of insect repellents, correct clothing, bed nets and environmental control, complemented with chemoprophylaxis will greatly reduce this risk. The current South African guidelines to prevent a malaria infection include atovaquone-proguanil, doxycycline and mefloquine, with the latter drug recommended during pregnancy and when breast-feeding. Patients should be cautioned that despite implementing preventative measures, they should seek immediate medical attention if they develop 'flu-like' symptoms or a fever when returning from a malaria area. Appropriate prophylactic measures are key components in preventing a malaria infection and can be life-saving.
\end{abstract}

Keywords: malaria, prophylaxis, Anopheles, insecticides, South Africa

\section{Introduction}

With the summer holidays fast approaching, holidaymakers will be planning their trip across Africa and the globe. Patients need to be aware of the risks of mosquito bites and malaria, especially during the period of September to May when there is a moderate to high risk of contracting malaria. As such, the patients should be informed of the various options available in the form of preventative measures and chemoprophylaxis. ${ }^{1}$ Patients should be advised on the ' $A B C$ ' of malaria prevention, which include A: Awareness and Assessment of malaria risk; B: Avoidance of mosquito Bites; C: Compliance with Chemoprophylaxis, when indicated; D: Early Detection of malaria disease; E: Effective treatment. $^{2}$

\section{Malaria transmission}

Of the 91 countries reporting indigenous malaria cases in 2016, fourteen countries in sub-Saharan Africa and India suffered $80 \%$ of the global malaria burden, along with 356000 of the 445000 global malaria-associated deaths. ${ }^{2}$ Although the global incidence rate of malaria is estimated to have decreased by $18 \%$ over the past six years, there was still an estimated 194 million cases of malaria in the WHO African Region. ${ }^{2}$

In South Africa, the malaria-endemic areas are limited to the north-eastern part of South Africa in the north-eastern Limpopo, eastern Mpumalanga and northern KwaZulu-Natal (Figure 1). ${ }^{1}$ South Africans also remain at risk from Odyssean or imported malaria from countries such as Swaziland, Mozambique, Angola,
Zambia and Malawi where malaria is a risk throughout the year. ${ }^{2}$ Although the number of reported malaria cases has dramatically decreased since the last epidemic ten years ago, malaria still remains endemic in South Africa. ${ }^{2}$

\section{The malaria vector}

The larvae of the most common southern Africa species, namely An. arabiensis, An. funestus and An. gambiae complex, are at home in a wide range of habitats where there is clean water for optimal growth. ${ }^{2,3}$ The adults can be carried by wind, where a few may be found further than 1-2 kilometres from their larval site. As such, the vicinity around the patient's home should be carefully monitored for freestanding water. With the current scarcity of water, many households may have installed water barrels to conserve rainwater. It is essential that these reservoirs be adequately covered to prevent eggs from being laid in these ideal conditions.

\section{Bite avoidance}

In South Africa, some mosquitoes, such as An. funestus and An. gambiae tend to favour resting indoors; whilst An. arabiensis can be found resting in the bush outdoors, as well as indoors. If a patient is outdoors during dusk to dawn, it is recommended that they wear clothing that covers as much of the body as possible, such as long sleeved clothing and long trousers. ' Light coloured clothing will be less of an attractant than dark coloured clothing to a mosquito; but the exact colour may not be enough of a deterrent, especially if the female mosquito requires a blood meal 


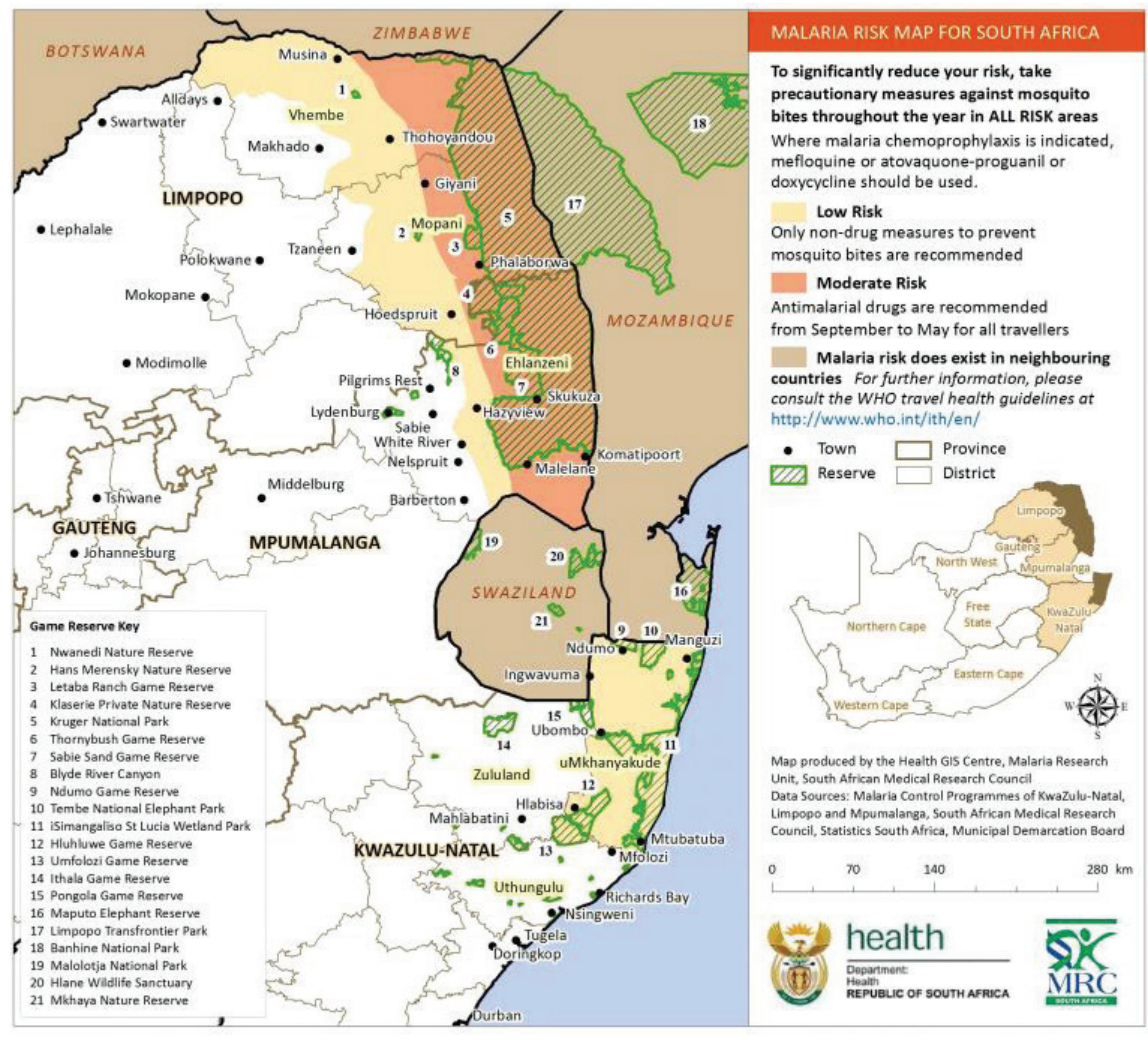

Figure 1: Malaria transmission areas in South Africa. ${ }^{1}$

to provide the essential nutrients for egg production. Mosquitoes are preferentially attracted to exhaled carbon dioxide, as well as body temperature and odour. ${ }^{4}$ As such, repellents that are sprayed on the body and clothing can provide some protection to the patient from becoming the next blood meal. Thin clothing will lend little protection to the bite of a mosquito, and in the hot weather it would be more comfortable and convenient to spray an insecticide repellent on the clothing or apply it to the skin, rather than wearing thick clothing. All three of the main vectors in southern Africa prefer to feed close to the ground, making unprotected lower legs, ankles and feet the preferred target regardless of whether the host is indoors or outdoors. ${ }^{5}$ Thus it is especially important that an insect repellent such $20-50 \%$ diethyltoluamide (DEET) be applied to the lower legs and feet every 4-6 hours according to the manufacturer's instructions. ${ }^{2}$ DEET-containing repellents should not be topically applied on infants less than two months old. In these patients, citronella oil is the most effective plant extract. However, even in its pure form it is less active with a shorter duration of action than most DEETbased repellents and should be more frequently reapplied, every 40 to 90 minutes, for sustained efficacy. ${ }^{6}$ Products containing $20 \%$ picaridin or $30 \%$ oil of lemon eucalyptus have been found to provide effective protection for a long duration (7-8 hours). ${ }^{7}$

Patients should be warned of the various products freely available for purchase that claim to repel mosquitoes to prevent malaria infections. Many have not been scientifically validated and the environment in which they are to be used would greatly affect the potential efficacy of the product. Products such as citronella wristband that may deter a mosquito for a short period, will provide a sense of false protection once the aromatic oil dissipates. Devices or cell phone apps emitting ultrasonic sounds have not been shown to kill or repel mosquitoes adequately to ensure protection. Similarly, although UV light attracts insects into an electrocuting or sticky board trap, some mosquitoes will be killed or caught, but these devices cannot ensure that the number of mosquitoes in the area are significantly reduced to decrease the risk of being bitten. Similarly, the use of warm coloured LED bulbs to decrease the number of mosquitoes being attracted towards the house may not be effective enough to protect the family from being bitten. ${ }^{8}$

The South African Department of Health advocates to control the malaria vector and protect households from infections by undertaking indoor residual spraying (IRS) to control indoor mosquitoes, as well as outdoor spraying. ${ }^{3}$ Burning mosquito repellent citronella candles in open areas has been shown to be less effective than in areas of limited air movement. ${ }^{9}$ Other measures to protect household members include knockdown insecticidal sprays, burning insecticide coils, vapourising mats, sleeping under insecticide-treated bed nets and ceiling fans, along with treated mosquito screens on the doors and windows to provide additional protection. ${ }^{2,10}$

\section{Risk factors and infections}

There are several factors to consider when evaluating the risk of being infected with malaria. These include the area being visited, time of year, duration of stay, any outdoor activities between dusk and dawn, type of accommodation and mode of travel. Patients at higher risk for developing severe (complicated) malaria, should be carefully monitored and encouraged to either stay out of the malaria area or to take extra precautions when entering the malaria area. Such patients include, pregnant women, young children and infants, patients older than 65 years, immunocompromised patients (including HIV-infected, taking corticosteroids or on chemotherapy), patients with a history of splenectomy or comorbid conditions. ${ }^{1,2}$

\section{Chemoprophylactic drugs in South Africa}

According to the latest 2017 South African guidelines, the recommended chemoprophylatic drugs are still mefloquine, doxycycline or atovaquone/proguanil depending on the patient profile (Table I). ${ }^{1}$ The latter combination is the prophylaxis of choice as it is well tolerated, efficacious and importantly has improved compliance due to its shorter prophylactic course (Table I). Common adverse effects reported for this combination are gastric intolerance (usually subside), mouth ulcers and stomatitis. ${ }^{1,10}$ Ideally, pregnant women and young children should be discouraged from entering a malaria area due to the increased risk of being infected and the dire consequences 
Table I: Pharmacological profile of prophylactic drugs to be taken at the same time each day. , $10,11^{-1}$

\begin{tabular}{|c|c|c|c|c|}
\hline $\begin{array}{l}\text { Prophylactic } \\
\text { antimalarial agents }\end{array}$ & Dosing schedule & $\begin{array}{c}\text { Trade names } \\
\text { and Scheduling }\end{array}$ & Contra-indications & $\begin{array}{c}\text { Special } \\
\text { prescribers notes }\end{array}$ \\
\hline $\begin{array}{l}\text { Atovaquone/ } \\
\text { Proguanil }\end{array}$ & $\begin{array}{l}\text { Adults: } 1 \text { adult tablet ( } 250 \mathrm{mg} \text { atovaquone } \\
\text { plus } 100 \mathrm{mg} \text { proguanil) daily; starting one } \\
\text { day before entering area; continuing daily } \\
\text { while in area; daily for } 1 \text { week after leaving } \\
\text { area. } \\
\text { Children: } 1 \text { paediatric tablet ( } 62.5 \mathrm{mg} \\
\text { atovaquone plus } 25 \mathrm{mg} \text { proguanil); } \\
11-20 \mathrm{~kg}-1 \text { paed tablet; } \\
21-30 \mathrm{~kg}-2 \text { paed tablets; } \\
31-40 \mathrm{~kg}-3 \text { paed tablets; } \\
>40 \mathrm{~kg}-1 \text { adult tablet }\end{array}$ & $\begin{array}{l}\text { Malanil }{ }^{\circ} \text { tabs [S2] } \\
\text { NuMal }{ }^{\circ} \text { tabs [S2] } \\
\text { Malateq }{ }^{\circ}[\mathrm{S} 2] \\
\text { Mozitec }^{\circ} \text { tabs [S2] }\end{array}$ & $\begin{array}{l}\text { Children }<11 \mathrm{~kg} \text {, } \\
\text { severe renal impairment, not } \\
\text { established for use during } \\
\text { pregnancy and in lactation. }\end{array}$ & $\begin{array}{l}\text { Take with a fatty diet/ } \\
\text { milk, at the same time } \\
\text { each day }\end{array}$ \\
\hline Mefloquine & $\begin{array}{l}\text { Adults: } 1 \text { tablet }(250 \mathrm{mg}) \text { weekly; starting } \\
\text { one week before entering area; once a week } \\
\text { whilst in the area; once weekly for } 4 \text { weeks } \\
\text { after leaving the area } \\
\text { Children: } 5-20 \mathrm{~kg}-1 / 4 \text { tablet; } \\
21-30 \mathrm{~kg}-1 / 2 \text { tablet ; } 31-45 \mathrm{~kg}-3 / 4 \text { tablet; } \\
>45 \mathrm{~kg}-\text { adult dose }\end{array}$ & $\begin{array}{l}\text { Lariam }^{\circ} \text { tabs [S4] } \\
\text { Mefliam tabs [S4] }\end{array}$ & $\begin{array}{l}\text { Children }<5 \mathrm{~kg} \text { or } \\
<3 \text { months old, } \\
\text { depression, epilepsy, } \\
\text { anxiety, severe hepatic } \\
\text { or renal impairment, } \\
\text { thrombocytopaenia, cardiac } \\
\text { conduction abnormalities, } \\
\text { those needing fine motor } \\
\text { co-ordination }\end{array}$ & $\begin{array}{l}\text { Prophylaxis of choice } \\
\text { during pregnancy } \\
\text { Safe in lactation } \\
\text { Take after a meal with } \\
\text { plenty of fluid }\end{array}$ \\
\hline $\begin{array}{l}\text { Doxycycline } \\
\text { hydrochloride }\end{array}$ & $\begin{array}{l}\text { Adults: } 1 \text { tablet ( } 100 \mathrm{mg} \text { ) daily; starting one } \\
\text { day before entering area; continuing daily } \\
\text { while in area; daily for } 4 \text { weeks after leaving } \\
\text { area. } \\
\text { Children: } 31-45 \mathrm{~kg} \text { ( } 8-15 \text { years) }-2 \mathrm{mg} / \mathrm{kg} \text {; } \\
>45 \mathrm{~kg} \text { (> } 15 \text { years) - Adult dose }\end{array}$ & $\begin{array}{l}\text { A-Lennon doxycycline } \\
\text { [S2] } \\
\text { Cyclidox caps [S2] } \\
\text { Doxycyl }{ }^{\circ} \text { caps [S2] } \\
\text { Dumocin caps [S2] }\end{array}$ & $\begin{array}{l}\text { Pregnancy, } \\
\text { children }<8 y r s \text {, lactation }\end{array}$ & $\begin{array}{l}\text { Take with adequate } \\
\text { fluid in an upright } \\
\text { position, at the same } \\
\text { time each day }\end{array}$ \\
\hline
\end{tabular}

an infection could have on the developing fetus and newborn (Table I). ${ }^{10,11}$ Common adverse effects reported for mefloquine include; dizziness, vertigo, GIT disorders, headache, sleep disturbances, mood changes and visual disturbances. ${ }^{10}$ Similarly the GIT adverse effects (nausea, vomiting, diarrhoea, oesophagitis), along with photosensitivity and candidiasis are possible when taking doxycycline. ${ }^{10}$ To note, the dose of minocycline used to manage acne is not effective as a prophylactic antimalarial and the full dose of doxycyline is required to ensure optimal plasma concentrations to prevent an infection. ${ }^{10}$ Several potential drug interactions have been highlighted by the new 2017 South African Guidelines for Malaria Prevention and should be referred to before prescribing the antimalarial agent. ${ }^{1}$ Patients should be cautioned not to take medication or remedies recommended by non-medical professionals, especially chilli, garlic and vitamin B; even drinking a few gin and tonics ( $58.3 \mathrm{mg} / \mathrm{l}$ quinine) each evening will not protect against an infection. ${ }^{12}$

\section{Conclusion}

Asking the right questions, knowledge of the travel destination and sound medical advice are all critical to prevent malaria infections. Unfortunately, no prophylactic antimalarial agent is $100 \%$ effective due to factors such as drug pharmacokinetics, antimalarial drug resistance and patient non-compliance. As such, the use of both non-pharmacological and pharmacological interventions significantly decrease the risk of infection. Patients should be cautioned that despite taking the prophylaxis, they should seek immediate medical attention if they develop 'flulike' symptoms or a fever when returning from a malaria area. ${ }^{1,7}$ Appropriate prophylactic measures are key components in preventing a malaria infection and can be life-saving.

\section{Acknowledgements}

I wish to acknowledge MrTA Rants'o for reviewing the manuscript.

\section{References:}

1. South African Department of Health. South African Guidelines For The Prevention Of Malaria. 2018 [accessed Sept 2018]. Available from: http://www. nicd.ac.za/wp-content/uploads/2017/09/Guidelines-South-African-Guidelinesfor-the-Prevention-of-Malaria-2017-final.pdf

2. WHO. World Malaria Report 2017 [accessed Nov 2018]. Available from: http:// apps.who.int/iris/bitstream/handle/10665/259492/9789241565523-eng.pdf;jses sionid=54C97AB26D0E90CD7385933F5B4C707D? sequence $=1$

3. Brooke B, Koekemoer L, Kruger P, Urbach J, Misiani E, Coetzee M. Malaria vector control in South Africa. S Afr Med J. 2013;103:784-8.

4. Raji Jl, DeGennaro M. Genetic analysis of mosquito detection of humans. Curr Opin Insect Science. 2017;20:34-8.

5. Braack L, Hunt R, Koekemoer LL, et al. Biting behaviour of African malaria vectors: 1 . where do the main vector species bite on the human body? Parasite Vector. 2015;8:1-10.

6. Kongkaew C, Sakunrag I, Chaiyakunapruk N, Tawatsin A. Effectiveness of citronella preparations in preventing mosquito bites: systematic review of controlled laboratory experimental studies. Trop Med Int Health. 2011;16:802-10.

7. Bell EA. Insect repellents crucial to deter spread of mosquito-borne viruses. Infect Dis Child. 2016;29:24.

8. Burkett DA, Butler JF, Kline DL. Field evaluation of colored light-emitting diodes as attractants for woodland mosquitoes and other Diptera in North Central Florida. J Am Mosquito Control Assoc. 1998;14:186-95.

9. Fradin MS, Day JF. Comparative efficacy of insect repellents against mosquito bites. N Engl J Med. 2002;347:13-8.

10. SAMF. Antiparasitic products. In: Rossiter D, ed. South African Medicines Formulary. Cape Town: Health and Medical Publishing Group, 2016; p. 514-24.

11. WHO. Guidelines for the treatment of malaria. Third Edition. 2015 [accessed Jun 2018]. Available from: http://apps.who.int/iris/bitstr eam/10665/162441/1/9789241549127_eng.pdf

12. McCloskey KL, Garriott JC, Roberts SM. Quinine Concentrations in Blood Following the Consumption of Gin and Tonic Preparations in a Social Setting. J Analyt Toxicol. 1978;2:110-2. 